\title{
The Petroglyphs of Qeshlagh in Hamadan Province, Western Iran
}

\section{Yaghoub Mohamadifar, Esmail Hemati Azandaryani}

Department of Archaeology, University of Bu-Ali Sina, Hamadan, Iran

Email address:

yamohamadi@yahoo.com (Y. Mohamadifar), Hemati30@yahoo.com (E. H. Azandaryani)

To cite this article:

Yaghoub Mohamadifar, Esmail Hemati Azandaryani. The Petroglyphs of Qeshlagh in Hamadan Province, Western Iran. International Journal of Archaeology. Vol. 3, No. 2, 2015, pp. 17-21. doi: 10.11648/j.ija.20150302.11

\begin{abstract}
Qeshlagh is a region located in Hamadan Provence, Western Iran. The Petroglyphs of Qeshlagh is located $55 \mathrm{~km}$ to the south-east of Hamadan city, and $30 \mathrm{~km}$ from the town of Malayer in the north-west. Petroglyphs of Qeshlagh contain 70 motifs on the surface of 17 single flat boulders; these drawings have been formed on these stone pieces with rubbing, hammering or in few cases engraving techniques. The themes of the studied compositions include images of ibexes, dog's motifs and anthropomorphous ones and the most common motif is Ibexes. In addition, considering the existence of patina layers and effects of weathering on these petroglyphs, which made laboratory studies impossible, we cannot suggest an absolute dating for them.
\end{abstract}

Keywords: Iran, Hamadan, Qeshlagh, Petroglyph

\section{Introduction}

This type of rock art has been formed by human on the beds of rocks and stones; the goal of creating such works of art could be related to the subsistence base (daily life and also daily needs to food and accommodation) or beyond it including rituals, art, perceptions, law, conventions, and social norms. This art has a united grammar and a universal repetitive pattern which encompass designs of animals, human, symbols, and geometric shapes in abstract styles and unbelievably realistic in much smaller scales in comparison with the real world. Extent and complexity of the topic of rock arts are contingent on the qualitative and quantitative variety of artifacts. Usually scenes of hunting or fighting, and sometimes dancing or performing rituals have been depicted on these rock panels. These remnants have been made on these stones and rock beds in particular environmental and ecological contexts in various styles in terms of form and content (Karimi 2007. 20). In term of the largest petroglyphic complexes in the western of the Iranian plateau. According to what has been said, the petroglyphs of Qeshlagh, their motifs, and their frequency are going to be discussed in the present paper; besides, it is to be mentioned that here the methodology of research and data gathering for this paper have been field work/survey, and the yielded data have been documented by the use of CorelDraw and Photoshop computer programs.

\section{Site Location}

Hamadan Province is located on the western Iran This province with an area of $19546.818 \mathrm{~km} 2$ is a part of Iranian highlands which is surrounded by other provinces such as Zanjan and Qazvin in the north, Lurestan in the south, Markazi in the east, and both Kermanshah and Kurdistan in the west (Fig. 1). Hamadan generally has a cold climate during winter and a mild one in summer, and it has lush green vegetation too. All these features along with good supply of water resources create an appropriate situation for both a nomadic lifestyle and cultivation. The Petroglyphs of Qeshlagh is located $55 \mathrm{~km}$ to the south-east of Hamadan city, and $30 \mathrm{~km}$ from the town of Malayer in the north-west. The complex of rock carvings, known locally as Qeshlagh is located: N 34284181, E 48393291. 


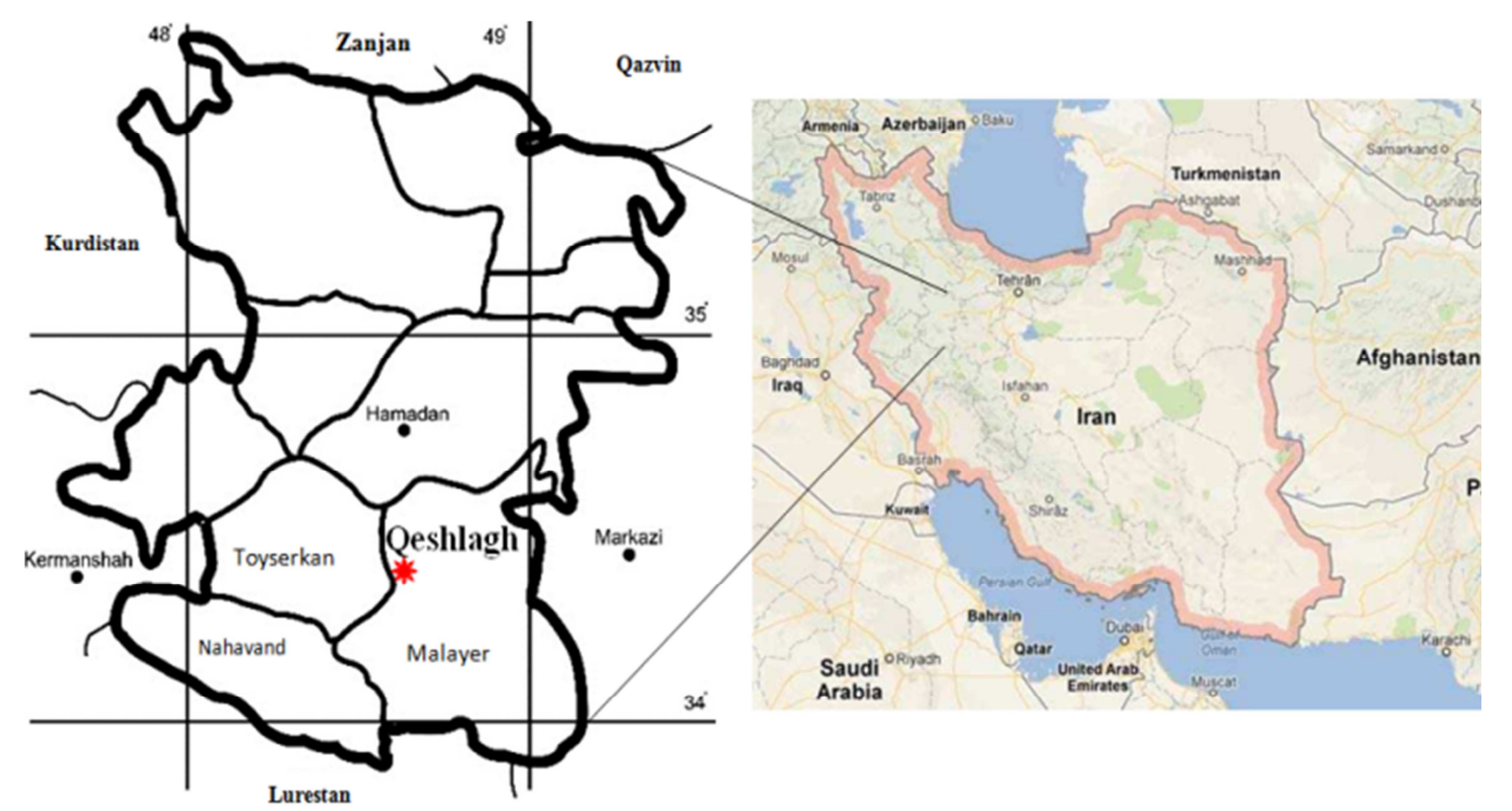

Fig. 1. The location of rock art in Qeshlagh, Hamadan, Iran.

\section{Research Background}

Petroglyphs are regarded as one of the most outstanding artistic cultural remains in different fields of study, such as archaeology, history of art, social sciences and so on. So far, a large number of such petroglyphs have been identified from different parts of Iran, including the Timareh (Farhadi 1988), Kurdistan (Lahafian 2004\&2010), Arasbaran (Rafifar 2005), GalehBozi (Ghasrian 2006), Sangestoon (Mohamadi Ghasrian 2007), Eshkaft Aho Bastak (Asadi 2007) and Basin area (Azizi Kharanaghi et al 2011) could be mentioned have been published as well; also, we could name petroglyph of Dare Divin Alvand (Saraf 1997), Haj Mad Farm and Moradbeig Valley (Rashidi Nejad \& Zamaniyan 2009), Cheshmeh Malek and Dareh Divin (Rashidi Nejad et al 2012), Azandaryan (Hemati Azandaryani et al 2014) and Dostali Valley (Hemati Azandaryani et al 2014) in Hamadan province as surplus examples too.

\section{The Petroglyphs of Qeshlagh}

The Petroglyphs and other rock art forms in the region of Qeshlagh are the same as petroglyphs of Azandaryan and are wholly on the rocks and flat surfaces - referred to as yaghli ghieh by the locals - with highly dense schist having formed flat panels due to geological events. Geologically and taking petroglyphs' status into account, the boulders of this region have schist composition. This schist has special friable surfaces on which the rock could be easily broken or cut. These surfaces are completely flat which prepare the possibility of creating designs on them. Petroglyphs of Qeshlagh have been identified through a transect survey, and totally 70 of them were discovered in dispersal on 17 single boulders over a vast area (Fig. 2). The major technique applied in producing these petroglyphs is hammering, sometimes rubbing and very rarely engraving. Interestingly, the directions of the surfaces of these rocks are mostly, with a few exceptions, to the south, being subjected to the maximum sunlight and also having a relative dominance over the nearby plain; they are also exposed to the regional and seasonal wind as well as the annual rainfall. These stylistic petroglyphs, which could be classified into four groups of anthropomorphic, ibexes, dogs and Symbolic according to their motifs, are sometimes single drawings and sometimes contextualized.

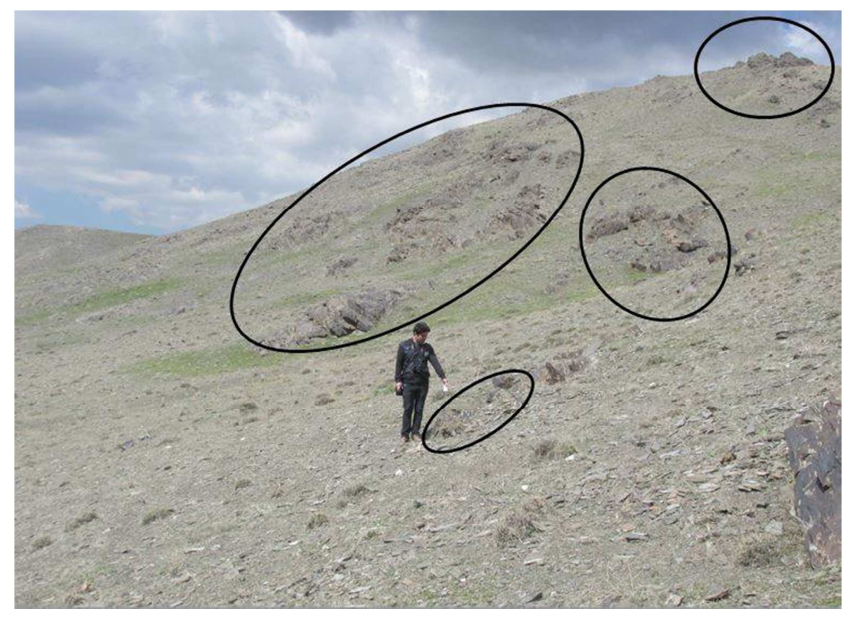

Fig. 2. Southern view of the site showing distribution of Qeshlagh petroglyph.

\subsection{Anthropomorphic Motifs}

There are often presented in singular and abstract forms. Sometimes humans ride a horse and at other times they are on foot. Considering their stylization, it is difficult to guess at their sex. The depicted scenes having nothing feminine, they are more likely men. A few contextualized scenes may have a narrative value. Among them, human riders are either with 
ibex or in a few other cases with dogs which could indicate hunting (Fig. 3). Some of these motifs are comparable to those found in Hamadan, Azandaryan.

\subsection{Ibex Motifs}

Among the petroglyphs of the Qeshlagh, ibex representations have two very long horns which draw more attention than the rest of the body. From our surveys, they are the most frequent petroglyph motif in the region (Figs. 4, 5, 6). They are comparable with those of the Azandaryan, Dostali Valley, Moradbeig Valley, Cheshmeh Malek and Dareh Divin. Scholars have diversely tried to explain their prominence, for example by considering the myth of ibex as the god of water (Schmandt-Besserat 1997). In addition, the ibex in the mythology of ancient Iran is one of the distinctive symbols of prosperity and abundance, as water is at their origin (Samadi 1988).

\subsection{Dog Motifs}

The motifs collectively interpreted as dogs are either seen in individual or narrative scenes. In individual ones, those 'dogs' have been displayed in profile and sometimes with oblong bodies, both in abstract patterns and with thick lines. In depicting this animal, no particular subtlety is observed. They are no more detailed than the ibex.

\subsection{Symbolic Motifs}

Some conventional drawings can be seen that certainly and meaningfully symbolize something (Fig. 7). Unfortunately, different study approaches such as analysing, investigating, comparing, collating and even ethno-archaeological studies on this cluster of motifs are not as easy to do as those on nature-oriented motifs; it is actually too demanding to attribute the unidentified motifs to their environs.
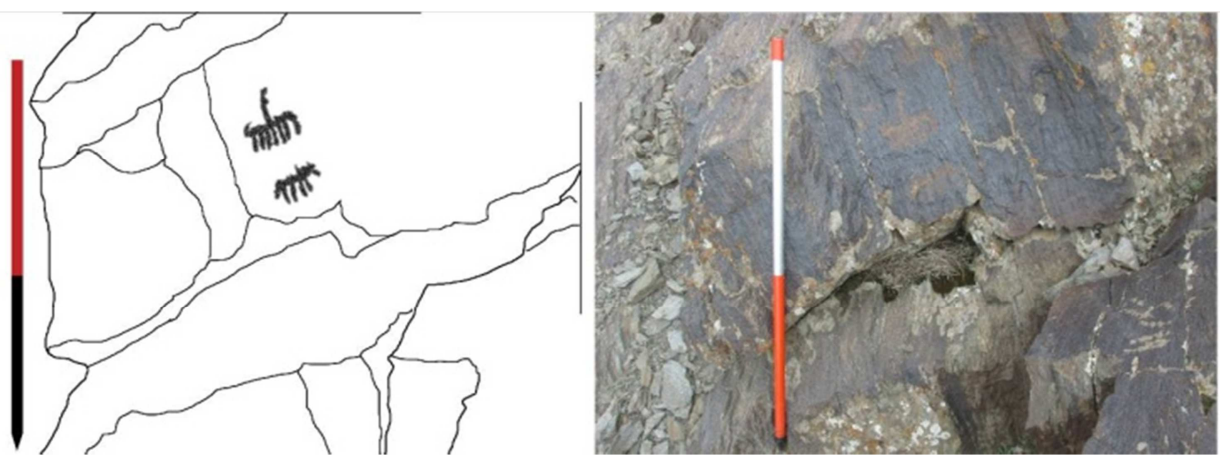

Fig. 3. Game and hunter on horseback, Qeshlagh.
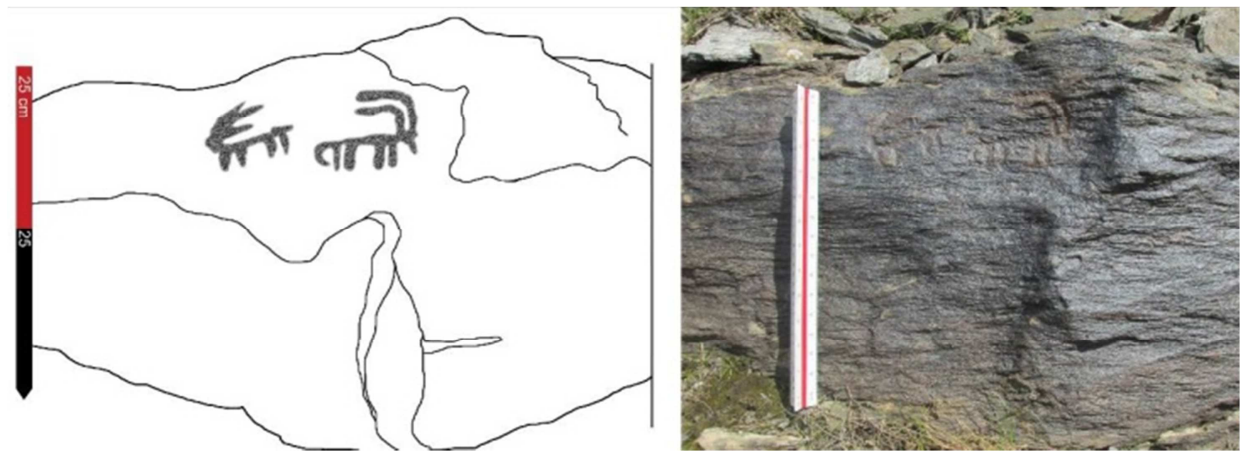

Fig. 4. Ibex with exaggerated long horns, Qeshlagh.
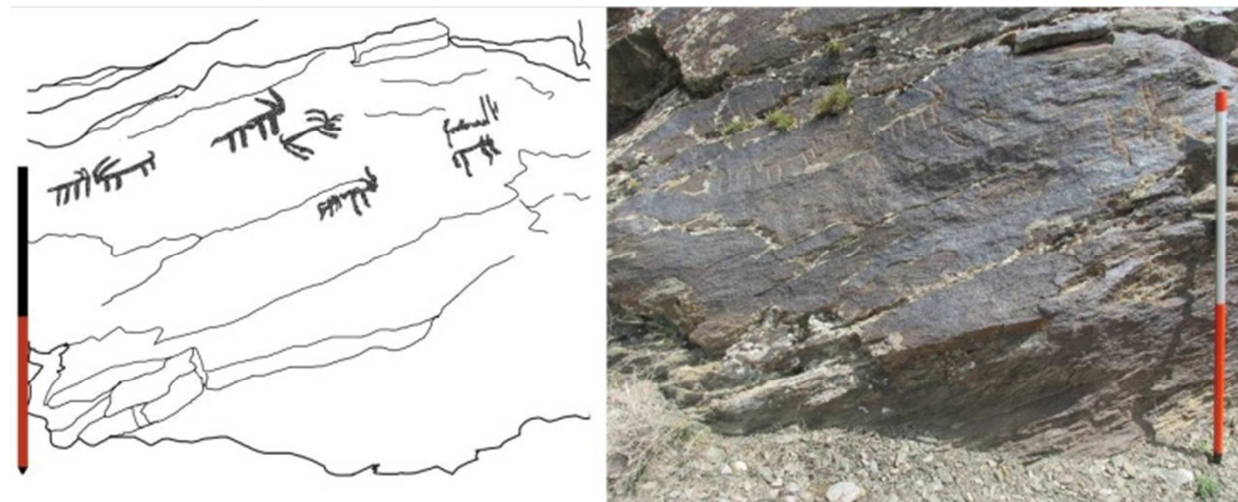

Fig. 5. Ibex motifs, Qeshlagh. 

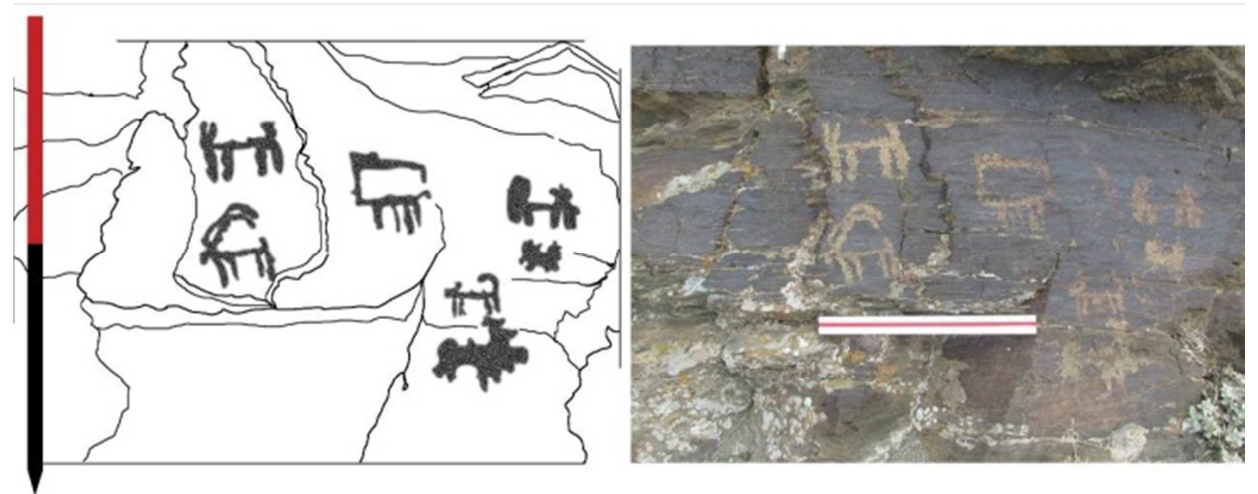

Fig. 6. View of the main group of petroglyphs at Qeshlagh.
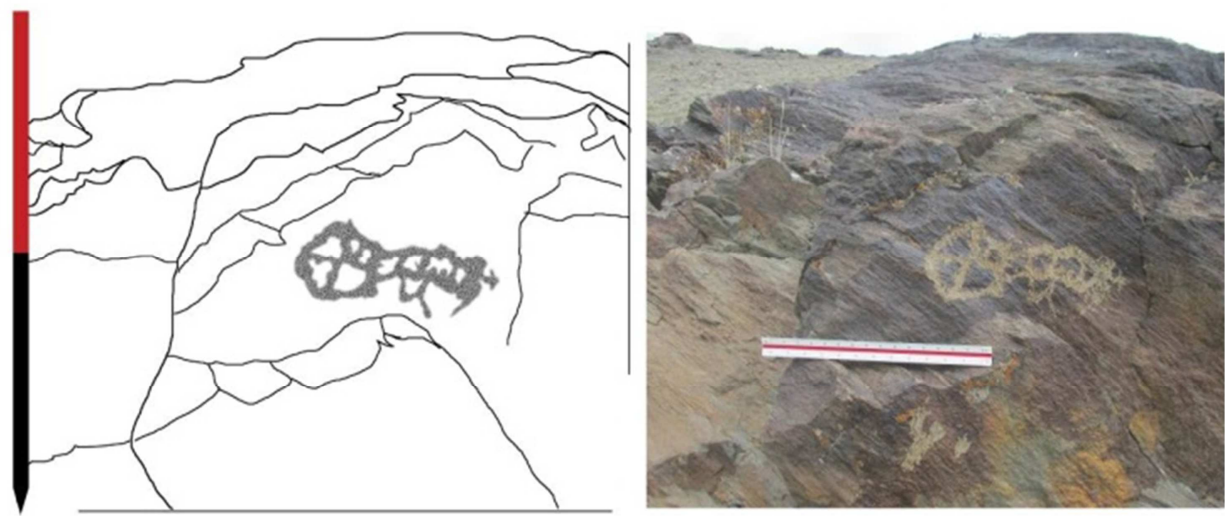

Fig. 7. The Symbolic motif of Qeshlagh.

\section{Chronology}

The petroglyphs of Qeshlagh are the same as other petroglyphs of Iran and have significantly different degrees of patina and varnish in this area, which shows that their time of production ranges over different time periods. However, no laboratory or field studies to determine their chronology has been conducted in Iran. Therefore, we cannot provide any form of chronology for the newly found petroglyphs of Qeshlagh.

\section{Conclusion}

In the region of Qeshlagh of Hamadan, 70 petroglyph designs have been identified and then comparing them with some other parallels in other different places of Iran or even beyond its frontiers indicates some uniformity in both topics and motifs. They could be compared with those of the Hamadan province both from their techniques (rubbing, hammering, and in a few cases engraving) and motifs. The petroglyphs we studied resemble mostly those of Qeshlagh Dali, Baghali Darasi, Ashaghi Kolangah, Ashaghi Nehanjah, Haj Mad Farm and Moradbeig Valley, Cheshmeh Malek and Dareh Divin. The most abundant motif in Qeshlagh is the Ibex, comparable with the other regions of Iran which have the most abundant ibex motif. Our subject petroglyphs, according to the environmental and climatic conditions, bear various amounts of patina and weathering trace, which indicates different widespread groups of designs in Qeshlagh village have been formed in different periods of time and putting all of them in one united time span is undoubtedly wrong. However, no laboratory or field studies to determine their chronology has been conducted in Iran, so we cannot provide any form of chronology for the newly found petroglyphs of Qeshlagh village.

\section{Acknowledgements}

We would like to thank Mehdi Mirzaei (may his memory be blessed); Hossein Rezaie Azandaryani, Hasan Hemati Azandaryani, Morteza Saraie and Mohammad Shaabni for help us.

\section{References}

[1] Asadi, A. 2007. Eshkft-e Aahou, a Rock Shelter in Bastak District, Hormozgan. Bastanpazhuhi, 2(3): 65-70 (in Persian).

[2] Azizi Kharanaghi, M. Naseri, R. Panahi Pour, M and Barani, M. 2011. Petroglyphs discovered in the Basin Area of The Upper Gotvand Dam (BARD-E PAZANI, IRAN). Journal of INORA 61: 9-19.

[3] Farhadi M. 1998. Museums in wind. University of Allame Tabatabayi, Tehran (in Persian).

[4] Ghasrian S. M. 2006. Rock engraving of GalehBozi Mountain in Esfahan. Bastanpazhuhi. 2(3): 62-63 (in Persian). 
[5] Hemati Azandaryani, E. Mohamadifar, Y. Hejebri Nobari, and Khanali, H. 2014. Azandaryan: newfound petroglyphs in Hamadan, western Iran. Rock Art Research. 31(2) (in press).

[6] Hemati Azandaryani, E. Rahmani, E. Masjedi Khak, P. and Aliei, M. 2014. The newfound petroglyphs in Dostali valley of Hamadan, western Iran, Journal of INORA (in press).

[7] Karimi, F. 2007. A New Insight into the Rock Engravings of Iran Based on Field Investigations. Bastanpazhuhi, 2(3): 20-34 (in Persian).

[8] Lahafian, J. 2004. Petroglyphs of Kurdistan. Rock Art Research. 21(1): 3-10.

[9] Lahafian, J. 2010. Cupules in Kurdistan Rock Art. Rock Art Research. 27(2): 177-183.

[10] Mohamadi, S. 2007. Sangestoon, A new rock art site in central Iran. Rock Art Research. 24(1): 59-64.
[11] Rafifar, J. 2005. Rack Carvings Art in Arasbaran. Tehran: Iranian Cultural Heritage and Tourism Organization Anthropology Research Center (in Persian).

[12] Rashidi Nejad, M. Salehi, A. M. Veisi, M. 2012. Cheshmeh Malek and Dareh Divin. Journal of INORA 62: 11-14.

[13] Rashidi Nejad, M. and Zamaniyan, M. 2009. Survey newfound petroglyphs of Mazrae Haj Mad and Dare Morad Beig of Hamadan. Payam Bastanshenas 11: 89-96 (in Persian).

[14] Samadi, M.1988. Month in Iran, from the most ancient times until the rise of Islam, Tehran: Scientific and Cultural Publishing Company (in Persian).

[15] Saraf, M. R. 1997. Rock Carving of Divin Valley of Alvand in Hamadan. Archaeological Report (1): 304-305 (in Persian).

[16] Schmandt-Besserat, D. 1997. Animal Symbols at AIN GHAZAL. Expedition. 39(1): 56. 